\title{
Análisis de la industria de la madera aserrada en México
}

\author{
Rogelio Flores-Velázquez ${ }^{1}$, Enrique Serrano-Gálvez, \\ Víctor H. Palacio-Muñoz ${ }^{1}$ y Gonzalo Chapela ${ }^{1}$
}

\section{RESUMEN}

Con la apertura comercial, los productos forestales mexicanos han enfrentado dificultades para acceder a los mercados internacionales y mantener su participación en el mercado interno disminuido las exportaciones y aumentado las importaciones, lo que se ha visto reflejado finalmente en un aumento del déficit de la balanza comercial. La industria del aserrío, la más importante tanto por el volumen que procesa como por el número de plantas industriales que existen, ha sido la más afectada. En los últimos seis años la importación de madera aserrada ha aumentado significativamente. Esto implica una mayor dependencia comercial de este producto, habiéndose cubierto gran parte del consumo nacional aparente de madera aserrada con importaciones provenientes de Chile, Estados Unidos, Brasil y Canadá. Para revertir esta tendencia, es urgente implantar una serie de políticas públicas en el mediano y corto plazo, que tiendan a fortalecer esta industria. De no hacerlo se preven efectos negativos, como una mayor presión sobre el bosque natural, el cierre parcial o total de aserraderos, aumento del desempleo y la pérdida de una importante fuente de ingresos para los propietarios del recurso forestal.

PALABRAS CLAVE:

Apertura comercial, industria del aserrío, productos forestales.

\section{ABSTRACT}

With commercial aperture, Mexican forest products have faced difficulties for accessing international markets and maintaining their participation in internal markets; exports have decreased and imports increased, with a consequent increase in trade-balance deficit. The sawn timber industry, the most important because of the volume that processes, as for the number of existent industrial plants, has been the most affected one. In the last six years, the lumber imports have increased significantly. This implies greater commercial dependence of this product, supplying great part of the lumber apparent national consumption with imports coming from Chile, the United States, Brazil and Canada. To reverse this tendency, it is urgent to implement a series of public policies aimed at strengthening this industry in the medium and short terms. Otherwise negative effects are sure to show, such as greater pressure on natural forests, partial or total closing of sawmills, unemployment increase, and loss of an important source of revenue for the owners of the forest resource.

KEY WORDS:

Commercial aperture, sawing industry, forest products.

1 Universidad Autónoma Chapingo, CIESTAAM. km. 36.5 Carretera Federal México-Texcoco, CP 56230, Chapingo, Edo de México. ce: flores.rogelio@inifap.gob.mx; segechap@hotmail.com; palacios@hotmail.com; gchapela@att.net.mx 


\section{INTRODUCCIÓN}

Con el ingreso de México al Acuerdo General de Aranceles y Comercio (GATT) en 1986 y la posterior apertura comercial, el sector forestal ha demostrado su falta de competitividad, lo que se refleja en la dificultad de los productos forestales para acceder a los mercados internacionales y el consiguiente aumento de las importaciones. El resultado final es un creciente déficit de la balanza comercial forestal. La industria del aserrío, segunda en valor económico de la producción industrial forestal sólo después de la industria de la celulosa y el papel, se ha visto afectada. El diferencial de precios respecto a la madera importada ha incidido negativamente en la comercialización de maderas de segunda, tercera y cuarta clases. Estas se han visto desplazadas incluso por material de desecho proveniente de Estados Unidos (Caballero, 2000; Quiñonez, 1998; González, 1995).

Al analizar el comportamiento del número de plantas industriales de aserrío en los últimos años, se observa un crecimiento sustancial; lo que pudiera hacer pensar que esta es una industria en auge. Lo que sucede en realidad, es que con las facilidades otorgadas mediante la legislación forestal durante la década de los noventas se favoreció la pulverización de este tipo de industrias.

Esta industria se caracteriza en el país, por ser poco intensiva en capital, lo que significa que es posible operar pequeños aserraderos con modestas inversiones. A la vez, se ha mantenido la existencia de instalaciones de baja productividad con maquinaria y equipo de bajo nivel tecnológico que se caracterizan por la escasa eficiencia de conversión de la materia prima. Esto se traduce en un coeficiente de aserrío de $50 \%$. El resto se transforma en costeras, recortes, virutas y aserrín, y donde no es posible aplicar eficientemente las economías de escala. Si a lo anterior se agregan los altos costos de la madera en rollo, el resultado final es la ausencia de competitividad de la madera aserrada en los mercados internacionales. Por consecuencia hay desplazamiento en el mercado nacional por madera aserrada de otros países, entre los que se encuentran, en orden de importancia, Chile, Estados Unidos, Brasil y Canadá (Juárez y Hernández, 2002).

El presente trabajo muestra un análisis comparativo de las condiciones que han prevalecido en la industria del aserrío en el periodo de 1980 al 2004. Se incluye un breve panorama de esta industria, los niveles de producción, consumo aparente y la balanza comercial. El objetivo es evaluar el comportamiento de la industria de la madera aserrada durante el periodo de estudio y proponer algunas políticas públicas para mejorarlo.

\section{METODOLOGÍA}

Para realizar el análisis de la industria del aserrío en México, se llevó a cabo una exhaustiva revisión estadística y bibliográfica que comprendió el periodo de 1980 al 2004. Posteriormente se hizo un análisis comparativo de las condiciones prevalecientes en esta industria, en cuanto a número de aserraderos, producción, consumo aparente, importaciones y exportaciones de madera aserrada.

\section{La industria del aserrío}

La industria forestal en México históricamente se ha concentrado en las regiones donde se localizan los bosques de coníferas, particularmente en Durango, Chihuahua, Michoacán, Oaxaca, Estado de México y Jalisco. En cambio, en las regiones con mayor diversidad de especies, como es la del trópico se localiza un menor número de plantas industriales, 
debido a su menor volumen, lo que hace a las especies poco atractivas desde el punto de vista económico, además de la dificultad que representa su aprovechamiento, extracción e industrialización. En particular, la industria de aserrío es la que ha tenido el mayor peso relativo. En 1980, esta industria contaba con un $67,7 \%$ del total de plantas industriales forestales, le seguía en orden de importancia la industria de cajas de madera con un $24,2 \%$. Lo anterior significa que si se toma en cuenta la relación entre estas industrias, dado que la madera que no se aprovecha en los aserraderos se utiliza como materia prima para la industria de cajas, en conjunto estas dos industrias aportaban un $91,9 \%$ del total de las plantas industriales forestales. Le seguían en orden de importancia la industria de la celulosa y el papel con un $3,8 \%$ y la de tableros con un $2,9 \%$ (CNIDS, 1981).

La SEMARNAT en el 2003 registró 3497 industrias forestales, de las cuales el $88,6 \%$, es decir, 3098 plantas pertenecen a la industria del aserrío, cajas de empaque de madera y talleres de secun- darios. Las restantes 399 plantas se distribuyeron en fábricas de muebles (60), de chapa y triplay (48), de tableros (17), impregnadoras (11), de celulosa (7) y otros establecimientos que no reportan giro industrial (256) (SEMARNAT, 2005).

En lo que respecta al número de aserraderos, en el periodo de 1980 al 2003, se observa un comportamiento a la alza, al pasar de 1396 a 2 058, lo que significó un crecimiento del $47 \%$. Esto se explica por la desregulación a que dio lugar la legislación forestal para la instalación de este tipo de establecimientos en la década de los noventa. Como se muestra en la figura 1, el número de aserraderos existentes disminuyó a partir de 1984 y alcanzó en 1987 su valor más bajo (898 plantas). A partir de ese año, se incrementó el número de plantas instaladas. A partir de 1991 aumentó nuevamente el número de aserraderos y en 1999 alcanzó su valor máximo con 2058 aserraderos, mismo número que se mantuvo hasta el 2003.

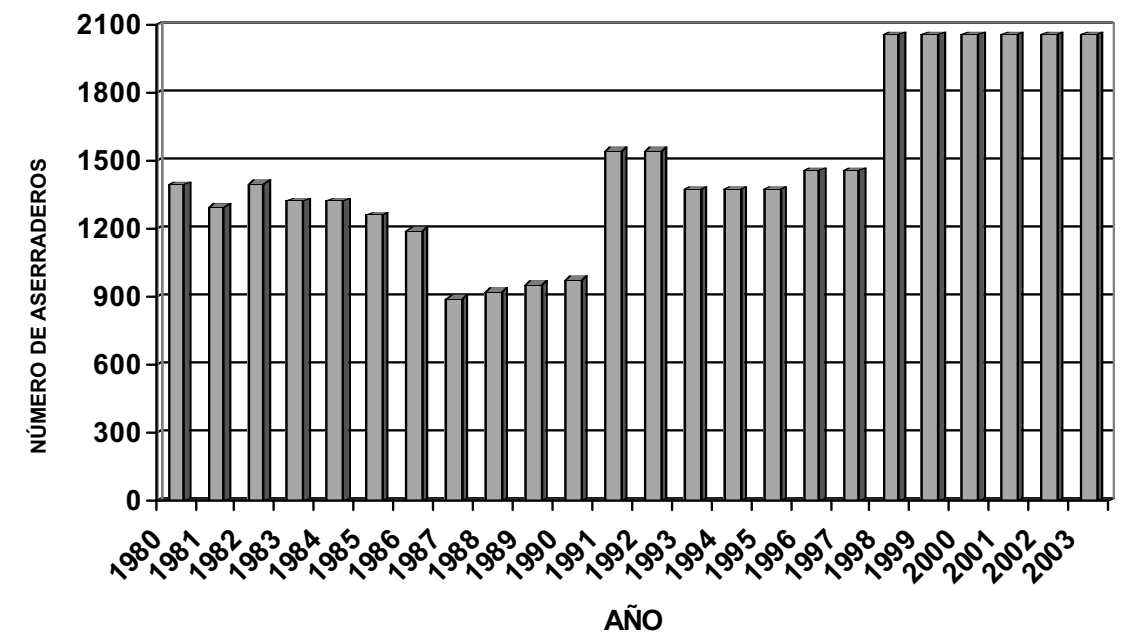

Figura 1. Comportamiento del número de aserraderos en México. 
Aún cuando el número de plantas disminuyó en el lapso de 1984 a 1987, la capacidad instalada aumentó en este periodo, a una tasa de crecimiento promedio anual de 3,5\%. De 1987 al 2003, esta misma capacidad aumentó a una tasa de crecimiento promedio anual de $2,4 \%$. A pesar de aumentar su capacidad instalada, la industria del aserrío no fue capaz de incrementar su capacidad utilizada, e incluso, ésta ha disminuido al paso del tiempo, de $82,1 \%$ en 1980 a $55,9 \%$ en el 2003. La razón de esta tendencia a la baja se debe a varios factores: al verse incrementada la capacidad instalada, los requerimientos de materia prima también aumentaron. Si se revisa el comportamiento de la producción del sector forestal para el mismo periodo, ésta se mantuvo casi constante, lo cual derivó en una mayor capacidad ociosa en la industria al aumentar el número de aserraderos y no tener un abastecimiento seguro y continuo. Otra causa de este comportamiento se encuentra en el tiempo muerto por falta de mantenimiento a equipos o bien por ineficiencia de personal.

Al relacionar la ubicación con el tamaño de la industria forestal, las industrias medianas y grandes se localizan en los estados forestales más importantes del país, es decir, Chihuahua, Durango, Jalisco, Oaxaca y México, principalmente. El caso de Michoacán reviste particular atención, ya que si bien es el estado con mayor número de plantas forestales, también lo es que el $98 \%$ está constituido por micro y pequeñas industrias.

Finalmente, en términos de generación de empleos la actividad forestal es poco relevante en la economía global mexicana. De acuerdo con Carballo et al. (1990), para el periodo de 1980 a 1989 el número de empleos en la industria forestal osciló de 75033 a 80460 . Durante el período de 1990 a 2001, las ocupaciones remuneradas en la silvicultura disminuyeron de 88600 a 84300 y en la industria maderera de 148900 a 110 700 ; esto significó una disminución total en este periodo de aproximadamente $17,89 \%$.

\section{El contexto mundial}

La producción y consumo mundial de madera aserrada en las dos últimas décadas, se estancó e incluso disminuyó. En general, la producción mundial de madera aserrada durante el periodo de 1980 al 2003, disminuyó a una tasa promedio anual de $0,5 \%$. Los niveles de producción más bajos ocurrieron en 1998 y 2001. La producción en 2001 fue de 376,88 millones de $\mathrm{m}^{3}$ aserrados similar a la de 1998 (375,31 millones de $\left.\mathrm{m}^{3}\right)$, habiéndose alcanzado la producción más alta en 1988 con 510,28 millones de $\mathrm{m}^{3}$.

La tabla 1 muestra la producción mundial de madera aserrada en 2003 destacando Estados Unidos y Canadá, quienes produjeron el $22,15 \%$ y el $14,31 \%$, respectivamente del volumen mundial. En este contexto, México participó con el $0,57 \%$.

En relación con la producción maderable nacional, actualmente siete millones de hectáreas se encuentran bajo manejo forestal regulado. Durante el período de 1980 a 2004 la producción promedio anual fue de 8,2 millones de $\mathrm{m}^{3} \mathrm{r}$ y registró una disminución de 9,95 millones de $\mathrm{m}^{3} \mathrm{r}$ en 1985, año en que alcanzó su máximo; a 6,3 millones $\mathrm{m}^{3} \mathrm{r}$ en 1995, año en que alcanzó su mínimo. En el 2004 el volumen de la producción fue de 7,79 millones $\mathrm{m}^{3} \mathrm{r}$ (Fig. 2) (CNIDS, 1980-1988; CNIF, 1987-1994; SEMARNAP 1998-2000; SEMARNAT 2001-2005).

El comportamiento nacional de la producción de madera aserrada en las últimas dos décadas, muestra una 
Tabla 1. Producción mundial de madera aserrada (2003)

\begin{tabular}{|l|c|c|}
\hline \multicolumn{1}{|c|}{ País } & Volumen ${\mathbf{( m i l l ~} \mathbf{~}^{\mathbf{3}} \text { ) }}^{\text {Porcentaje }}$ \\
\hline EU & 89,042 & 22,15 \\
\hline Canadá & 57,546 & 14,31 \\
\hline Brasil & 21,200 & 5,27 \\
\hline Federación Rusa & 19,639 & 4,88 \\
\hline Alemania & 17,596 & 4,38 \\
\hline Suecia & 16,800 & 4,18 \\
\hline Japón & 14,402 & 3,58 \\
\hline Finlandia & 13,745 & 3,42 \\
\hline Austria & 10,473 & 2,60 \\
\hline Francia & 9,605 & 2,39 \\
\hline China & 9,431 & 2,35 \\
\hline India & 7,900 & 1,96 \\
\hline Indonesia & 6,500 & 1,62 \\
\hline Chile & 6,439 & 1,60 \\
\hline Turquía & 5,615 & 1,40 \\
\hline República de Corea & 5,194 & 1,29 \\
\hline México & 2,290 & 0,57 \\
\hline Otros & 88,617 & 22,05 \\
\hline Total mundial & 402,034 & 100,00 \\
\hline
\end{tabular}

Fuente: Elaboración propia con datos de FAOSTAT $(F A O, 2005)$

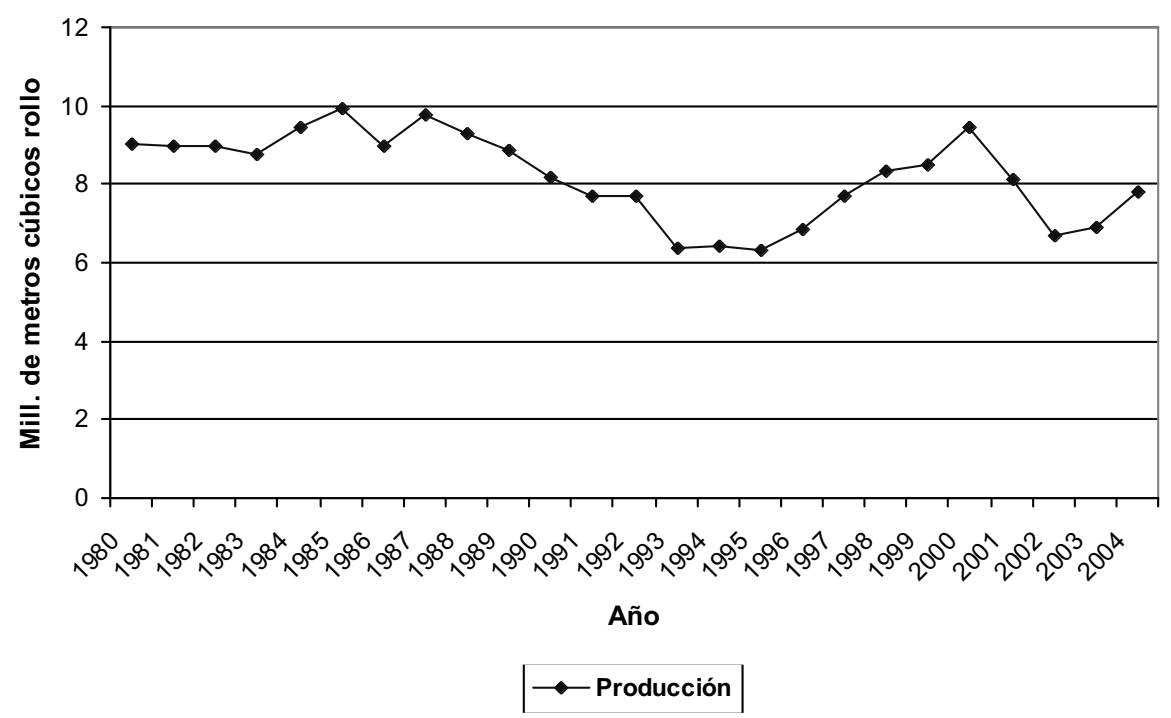

Figura 2. Producción maderable en México. 
tendencia irregular, alcanzándose los valores máximos de producción en los años de 1987 y 2000 con 3,24 y 3,27 millones de $\mathrm{m}^{3}$ aserrados, respectivamente. Uno de los menores volúmenes de producción tuvo lugar en 1995, siendo este de 2,33 millones de $\mathrm{m}^{3}$ (Fig. 3). Este último valor se explica en función de la contracción del mercado como consecuencia de la devaluación del peso mexicano de 1994.

A partir de 1996, se observa una tendencia a la alza en los volúmenes de producción de madera aserrada hasta alcanzar en el año 2000 la cifra histórica de 3,27 millones de $\mathrm{m}^{3}$. Para el 2001 disminuyó nuevamente, y llegó a su valor más bajo en el 2003 (2,29 millones de $\mathrm{m}^{3}$ ), lo cual se explica por la agresiva entrada en el mercado nacional de la madera aserrada chilena y a la sobre valuación del peso mexicano.

\section{Comercio internacional}

En el largo plazo, el comportamiento de la producción y consumo de madera es afectado por la oferta y la demanda. El consumo parece estar declinando, en parte debido a que en la última década inició la llamada desmaterialización de la economía. Es claro que los materiales están jugando un papel cada vez menos importante en las economías que transitan hacia la era de la informática y los servicios.

En la tabla 2 se observan los países con los mayores valores de flujo comercial de madera aserrada a nivel mundial. Destaca por el superávit de su balanza comercial Canadá, quien es el mayor exportador de madera aserrada, seguido por Suecia y Estados Unidos, siendo este último país el mayor importador de este producto.

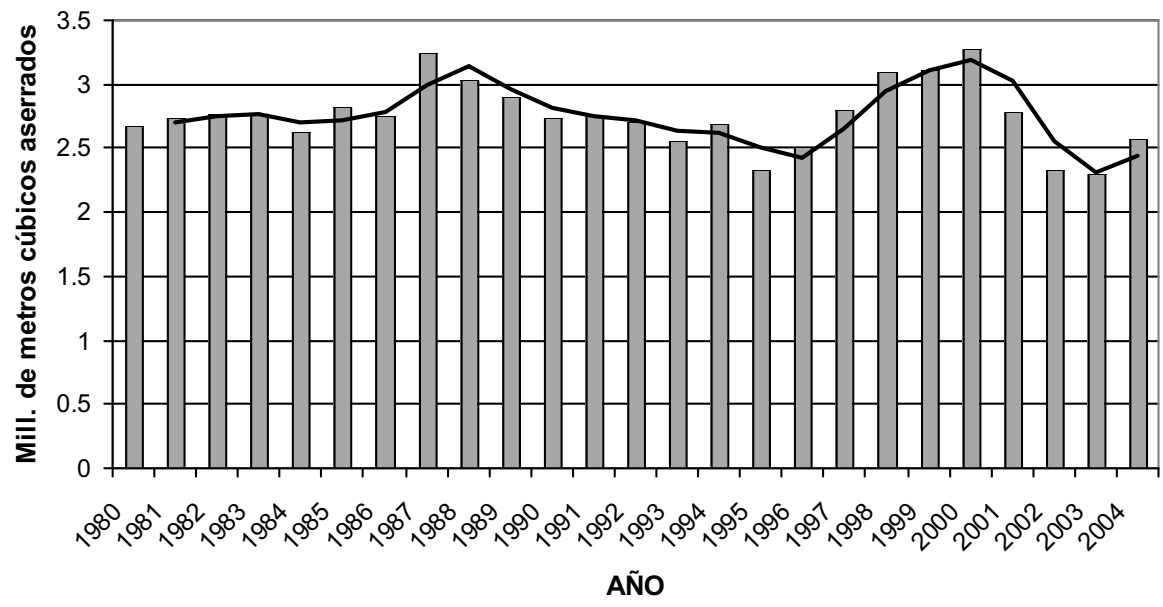

Figura 3. Producción de madera aserrada en México.

Fuente: Elaboración propia con datos de CNIDS y CNIF hasta 1994; SEMARNAP 1998-2000; SEMARNAT 20012005; Fox 2004. Los datos fueron ajustados para transformar a madera aserrada empleando un coeficiente de transformación de 0.5 . 
Tabla 2. Exportadores e importadores de madera aserrada en el mundo (2003)

\begin{tabular}{|l|c|c|c|}
\hline País & $\begin{array}{c}\text { Exportaciones } \\
(1000 \text { US\$) }\end{array}$ & $\begin{array}{c}\text { Importaciones } \\
(1000 \text { US } \$)\end{array}$ & $\begin{array}{c}\text { Balanza Comercial } \\
(1000 \text { US\$) }\end{array}$ \\
\hline Canadá & 6456789 & 473024 & 5930477 \\
\hline Suecia & 2506205 & 139972 & 2366233 \\
\hline Finlandia & 1652596 & 86268 & 1566328 \\
\hline Federación Rusa & 1177321 & 4259 & 1173062 \\
\hline Austria & 1286491 & 305981 & 980510 \\
\hline Indonesia & 673126 & 47872 & 625254 \\
\hline Malasia & 692544 & 104905 & 587639 \\
\hline Brasil & 548941 & 59087 & 489854 \\
\hline Letonia & 505512 & 51272 & 454240 \\
\hline Rumania & 427238 & 4854 & 422384 \\
\hline Nueva Zelanda & 376647 & 24868 & 351779 \\
\hline Alemania & 1048176 & 1079923 & -31747 \\
\hline Tailandia & 229786 & 340313 & -110527 \\
\hline Bélgica & 325202 & 573512 & -248310 \\
\hline México & 22774 & 345511 & -322737 \\
\hline Dinamarca & 51729 & 561194 & -509465 \\
\hline Francia & 319925 & 906713 & -586788 \\
\hline Países Bajos & 130322 & 799573 & -669251 \\
\hline España & 52218 & 927580 & -875362 \\
\hline China & 350198 & 1880806 & -1450608 \\
\hline Italia & 103726 & 1791075 & -1687349 \\
\hline Reino Unido & 76230 & 2004287 & -1928057 \\
\hline Japón & 11734 & 2673306 & -2661572 \\
\hline EU & 1691108 & 5988865 & -4297757 \\
\hline
\end{tabular}

Fuente: Elaboración propia con datos de FAOSTAT (FAO, 2005)

Entre los países que mantienen una parte importante del flujo comercial de este producto se encuentran Japón, Suecia, China y Alemania. México se ubica en el lugar 15, lo que pone de manifiesto su escasa importancia, en comparación con sus socios comerciales del norte, no obstante se encuentra por arriba de Chile (lugar 29), que ha sido su principal abastecedor en los últimos años y quien se caracteriza porque sus importaciones de este producto son mínimas, con lo que disminuye el valor de su flujo comercial.

\section{Balanza comercial}

México ha sido tradicionalmente un país importador de productos forestales. Las mayores importaciones han estado relacionadas con la producción de papel, pero en los últimos años la importación de madera aserrada ha aumentado significativamente. En 1980, el valor de las importaciones de madera aserrada fue de US \$ 66,547 millones, aumentando en 1981 a US \$ 74,335 millones, disminuyendo a partir de 1982 como resultado de la crisis económica hasta 1987, año en el que tuvo un valor similar al de 1981. Como se observa en la tabla 3, a partir de 1987, con excepción de 1989, las importaciones han tendido a incrementarse hasta 1993, lo cual se dio a una tasa promedio anual de 23,08\%. Durante el periodo de 1994 a 1996, como resultado de la crisis económica las importaciones disminuyeron a una tasa promedio anual de $17,26 \%$ presentando valores menores a los observados en 1993. De 1998 al 2004, se observa nuevamente una tendencia a incrementar, lo que ocurre a una tasa promedio anual de $16,11 \%$. 
Uno de los factores que ha estimulado o explica el aumento de la importación de madera aserrada es que el precio de la madera aserrada elaborada en México no es competitivo con el precio internacional. Cuando lo es, o su calidad es inferior al producto extranjero o no existe garantía en su abastecimiento en cuanto a volumen y oportunidad. Otro factor es la falta de desarrollo sustentable tanto en la producción como en la industria nacional sobre bases de un cultivo moderno del recurso y de la integración de ésta al mismo. Es evidente que la apertura comercial ha incidido en el aumento de la importación de madera aserrada.

El valor de las exportaciones de 1980 a 1992 muestra una tendencia creciente, aún cuando en los años de 1985 y 1991 presentó drásticas disminuciones. En este periodo pasó de us $\$ 0,246$ millones en 1980 a us $\$ 131,203$ millones en 1992, lo que significó un incremento de us \$ 130,957 millones, equivalente a un aumento del 53 234\% con respecto al año de 1980. En esta etapa se refleja el impacto de la crisis económica de la década de los ochenta. Disminuyendo en 1993 y 1994 a una tasa promedio anual de $46,31 \%$. A partir de 1995 y hasta 1997 se presentó una tasa de crecimiento promedio anual de 43,67\%. De 1997 al 2004, se observa una caída en el valor de las exportaciones pasando de us $\$ 112,147$ millones en 1997 a us $\$ 31,036$ millones en el 2004, lo que representó una disminución de us $\$ 81,111$ millones en ocho años (Tabla 3). Esto se explica en parte por la política económica de sobre valuación del peso mexicano, con respecto al dólar americano.

En el periodo de 1980 a 1990 se registró una tendencia decreciente en el déficit de la balanza comercial de madera aserrada, a una tasa promedio anual de $11,71 \%$, lo que se explica por la crisis económica que tuvo lugar en esta década. De 1991 a 1993, el déficit de la balanza comercial aumentó a una tasa promedio anual de $125,99 \%$, con una disminución del déficit en 1994 con respecto a 1993 , de us $\$ 12,230$ millones. Esto debido a la crisis económica de este año. Aunque los efectos de ésta se manifestaron claramente en los siguientes tres años cuando el déficit de la balanza disminuyó a una tasa promedio anual de $-42,17 \%$, pasando de us $\$-208.057$ millones en 1994 a us $\$-40,231$ millones en 1997. De 1998 al 2004, el déficit de la balanza comercial aumentó a una tasa promedio anual de $38,73 \%$.

En resumen durante el período de 1980 a 2004, con excepción de 1992 que tuvo un superávit, la industria del aserrío resultó con un saldo negativo en volumen debido a que las importaciones fueron mayores que sus exportaciones. En cuanto al valor de la balanza comercial, se presentó una situación similar, apareciendo la industria del aserrío en este periodo como deficitaria, con excepción de 1989, año en que presenta un superávit.

\section{Consumo nacional aparente}

El consumo aparente de madera aserrada se mantuvo constante o estable de 1980 a 1997, presentando una tendencia a la alza a partir de 1997 misma que se mantiene hasta el 2004. En contraste, la producción interna disminuyó en promedio $21,1 \%$ del 2000 al 2004, representando la producción mexicana de madera aserrada en el 2004 el $37,02 \%$ del consumo aparente (Fig. 4). Esto significa que los productores nacionales encontraron dificultades para comercializar sus productos debido a la pérdida de competitividad frente a las importaciones por el diferencial de precios y calidad.

Chile continuó con su agresiva incursión en el mercado mexicano de madera 
Tabla 3. Balanza comercial de madera aserrada de México

\begin{tabular}{|c|c|c|c|}
\hline Año & $\begin{array}{l}\text { Exportaciones } \\
\text { (1 } 000 \text { US } \$)\end{array}$ & $\begin{array}{c}\text { Importaciones } \\
\text { (1 } 000 \text { US\$) }\end{array}$ & $\begin{array}{c}\text { Balanza Comercial } \\
\text { (1 } 000 \text { US } \$)\end{array}$ \\
\hline 1980 & 246 & 66547 & -66301 \\
\hline 1981 & 359 & 74335 & -73976 \\
\hline 1982 & 225 & 38052 & -37827 \\
\hline 1983 & 3725 & 49936 & -46211 \\
\hline 1984 & 3725 & 36900 & -33175 \\
\hline 1985 & 982 & 39632 & -38650 \\
\hline 1986 & 5731 & 61348 & -55617 \\
\hline 1987 & 11158 & 74548 & -63390 \\
\hline 1988 & 34625 & 108799 & -74174 \\
\hline 1989 & 86997 & 40053 & 46944 \\
\hline 1990 & 89780 & 108867 & -19087 \\
\hline 1991 & 63066 & 155680 & -92614 \\
\hline 1992 & 131203 & 229198 & -97995 \\
\hline 1993 & 38904 & 259191 & -220287 \\
\hline 1994 & 37815 & 245872 & -208057 \\
\hline 1995 & 58559 & 142857 & -84298 \\
\hline 1996 & 94758 & 129838 & -35080 \\
\hline 1997 & 112147 & 152378 & -40231 \\
\hline 1998 & 68780 & 186232 & -117452 \\
\hline 1999 & 66085 & 204084 & -137999 \\
\hline 2000 & 36646 & 274745 & -238099 \\
\hline 2001 & 31706 & 278040 & -246334 \\
\hline 2002 & 30280 & 325870 & -295590 \\
\hline 2003 & 24737 & 345381 & -320644 \\
\hline 2004 & 31036 & 428959 & -397923 \\
\hline
\end{tabular}

Fuente: Elaboración propia con datos de FAOSTAT hasta 1992 (FAO, 2005) y Bancomext a partir de 1993.

aserrada ofreciendo un producto de aparente buena calidad y precios bajos, desplazando de este mercado incluso a Estados Unidos y convirtiéndose en los últimos años en el principal abastecedor (Juárez y Hernández, 2001, 2002 y 2003; Juárez y Arceo, 2004). En el 2003, Chile cubrió el $75,26 \%$ del volumen importado de este producto.

\section{PROPUESTAS}

La necesidad de una adecuada planeación que permita garantizar el abastecimiento de materia prima a la industria de manera consistente, oportuna y a precios competitivos se considera como fundamental para la industria de la madera aserrada. Los problemas de abastecimiento de materia prima están estrechamente ligados al aumento de la capacidad instalada, y al encarecimiento de la madera en rollo. Ello debido en parte a que la producción forestal maderable durante el periodo de estudio se mantuvo estable, en contraste con el incremento de su demanda como ya se mencionó.

En el aspecto del abastecimiento de materia prima a la industria de la madera aserrada, es necesario establecer estrategias y políticas de acción en relación con los programas de apoyo al sector forestal: Programa de Desarrollo Forestal (Prodefor), Programa Nacional de Reforestación (Pronare), Programa para el 


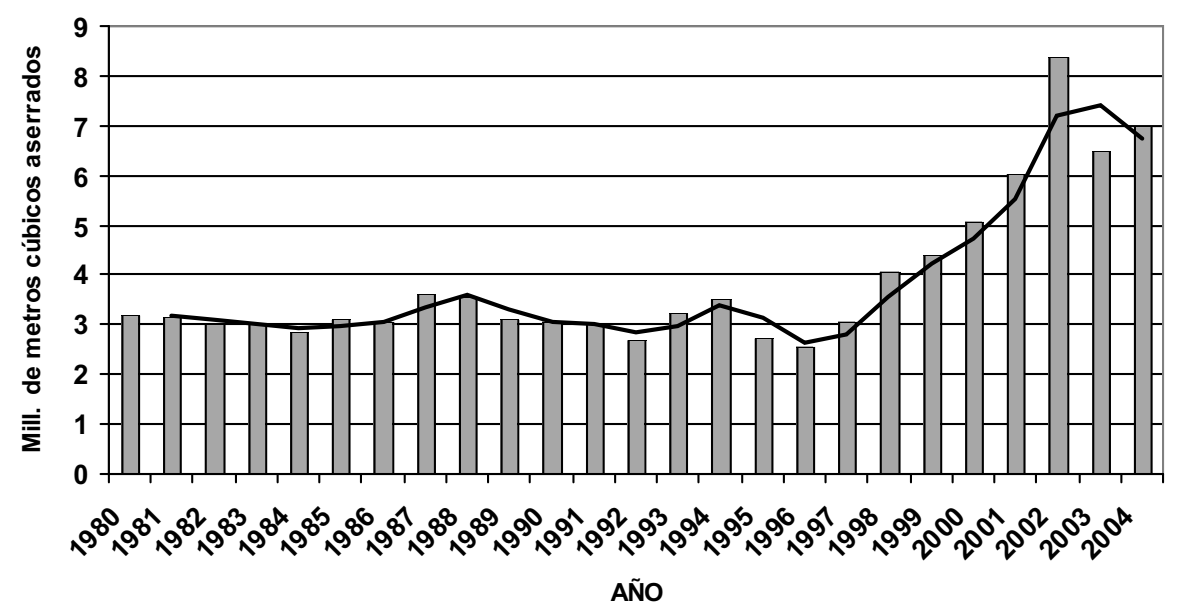

Figura 4. Consumo aparente de madera aserrada en México.

Fuente: Elaboración propia con datos de las memorias económicas de CNIDS* y CNIF*, los anuarios estadísticos de la producción forestal SEMARNAT*, FAOSTAT, Bancomext de 1999 a 2003, Fox (2004), Juárez y Hernández (2001, 2002 y 2003) y Juárez y Arceo (2004).

*Los datos fueron ajustados para transformar a madera aserrada empleando un coeficiente de transformación de 0.5 .

Desarrollo de plantaciones Forestales Comerciales (Prodeplan), entre otros, y con las prácticas dasonómicas utilizadas actualmente en México.

En cuanto a los programas forestales de apoyo, la queja generalizada es que los recursos están llegando de manera extemporánea. Los propietarios forestales requieren que los recursos autorizados se hagan llegar con oportunidad, para que estos programas rindan el fruto para el que fueron creados, que es el transitar hacia el desarrollo forestal sustentable. Por ejemplo, los recursos para control de incendios (elaboración de brechas cortafuego) se están entregando en la época de lluvias. Los recursos para reforestación se entregan cuando ha finalizado la temporada de lluvias. Además, se requiere establecer por lo menos un programa de apoyo que permita que la madera en rollo llegue a la industria del aserrío a precios competitivos. Esto con el fin de que la madera aserrada pueda competir tanto en el mercado nacional como en el internacional, lo que se podría dar por medio de un precio de garantía, como sucede en el área agrícola. Esto también disminuiría la tala clandestina.

Por lo que respecta a las prácticas dasonómicas, se sugiere que se realicen estudios sobre el aprovechamiento integral del árbol, para disminuir el desperdicio que permanece en el bosque y determinar su rentabilidad como fuente de materia prima para la industria de la celulosa. Además, se debe estimular la certificación de los productos forestales, tanto en lo referente a las plantaciones forestales como a los bosques nativos.

Por otro lado, se sugiere establecer un programa de capacitación para los empresarios y productores forestales del país de manera que puedan conocer las potencialidades y debilidades de su producto en los mercados donde se comercializa y cómo disminuir esas debi- 
lidades. Al mismo tiempo, se requiere desarrollar una industria menos fragmentada, más eficiente y competitiva. Es decir, plantas industriales de mayor tamaño o asociaciones de las existentes que les permitan utilizar las economías de escala y optimizar el uso de la madera en rollo. Ello redundará en un aumento de su coeficiente de aprovechamiento y una baja en los costos de producción, aumentando con esto la competitividad de esta industria.

Por último, se debe procurar que el marco institucional en materia forestal, a nivel nacional, estatal y municipal, coordine sus actividades e información para optimizar el uso de los recursos.

\section{CONCLUSIONES}

Dado el proceso de globalización mundial que exige un contacto comercial y financiero entre países con propósitos de intercambio, es necesaria la capacitación de los empresarios y/o productores forestales del país, para competir adecuadamente y reducir las desventajas con productores similares de otros países. Simultáneamente, se requiere desarrollar una planta industrial eficiente y competitiva, con el fin de aprovechar las ventajas comparativas de México e impulsar una política de Estado que incentive, promueva y fortalezca el desarrollo del sector, entre otras acciones.

Con el propósito de revertir la tendencia negativa que se observa en la industria del aserrío en México, es necesaria una serie de acciones de política en el corto plazo que tienda a fortalecer esta industria, tales como: flexibilizar las normas de operación de los programas de apoyo del sector forestal, inversión para modernizar la planta productiva y capacitación de la mano de obra. De no tomarse estas acciones se preven efectos negativos en el corto plazo, como el aumento de la tala clandestina, el cierre parcial o total de aserraderos, el aumento del desempleo y la pérdida de una importante fuente de ingresos para los propietarios del recurso forestal. En este sentido no se debe perder de vista la máxima que han expresado diversos actores en el sector forestal, de que la madera más barata continúa siendo la madera de contrabando.

Por lo anterior, se propone complementar el presente trabajo con un análisis de la integración de la cadena agroindustrial de madera aserrada que permita determinar sus debilidades y fortalezas para hacerla eficiente y competitiva en el ámbito internacional, así como identificar otras políticas públicas de apoyo y fomento a esta actividad.

\section{RECONOCIMIENTOS}

Este trabajo es parte del proyecto CONAFOR-2002-C01-6091 (CONAFOR-0201100200-0001) "Integración y desarrollo de cadenas productivas forestales en los estados de Tlaxcala, Puebla y Veracruz", financiado por el fondo sectorial CONAFORCONACYT.

\section{REFERENCIAS}

Caballero D., M. 2000. La actividad forestal en México. Universidad Autónoma Chapingo. Tomo I y II. México. 275 p. y 227 p.

Cámara Nacional de las Industrias Derivadas de la Silvicultura (CNIDS). 1981. Memoria económica 19801981. México. 84 p.

Cámara Nacional de las Industrias Derivadas de la Silvicultura (CNIDS). 1982. Memoria económica 19811982. México. 75 p. 
Cámara Nacional de las Industrias Derivadas de la Silvicultura (CNIDS). 1983. Memoria económica 1982 1983. México. 71 p.

Cámara Nacional de las Industrias Derivadas de la Silvicultura (CNIDS). 1984. Memoria económica 19831984. México. 76 p.

Cámara Nacional de las Industrias Derivadas de la Silvicultura (CNIDS). 1985. Memoria económica 19841985. México. 76 p.

Cámara Nacional de las Industrias Derivadas de la Silvicultura (CNIDS). 1986. Memoria económica 19851986. México. 81 p.

Cámara Nacional de las Industrias Derivadas de la Silvicultura (CNIDS). 1987. Memoria económica 19861987. México. 62 p.

Cámara Nacional de las Industrias Derivadas de la Silvicultura (CNIDS). 1988. Memoria económica 19871988. México. 60 p.

Cámara Nacional de la Industria Forestal (CNIF). 1989. Memoria económica. 1988-1989. México. 62 p.

Cámara Nacional de la Industria Forestal (CNIF). 1990. Memoria económica 1989-1990. México. 62 p.

Cámara Nacional de la Industria Forestal (CNIF). 1991. Memoria económica 1990-1991. México. 61 p.

Cámara Nacional de la Industria Forestal (CNIF). 1992. Memoria económica 1991-1992. México. 63 p.

Cámara Nacional de la Industria Forestal (CNIF). 1994. Memoria económica 1993. México. 28 p.
Carballo, Z. C. A., R. García de la Cadena V. y A. Rodríguez C. 1990. Diagnóstico macroeconómico de la industria forestal en México. Tesis profesional. División de Ciencias Forestales. Universidad Autónoma Chapingo. México. 173 p.

Food and Agriculture Organization of the United Nations (FAO). 2005. En línea: http://www.fao.org. Mayo 2005.

Fox Q., V. 2004. Anexo estadístico del cuarto informe de gobierno. México D.F. 720 p.

González, P. C. 1995. Los bosques de México y la banca internacional. Instituto de Investigaciones Económicas. Universidad Nacional Autónoma de México. México. 103 p.

Juárez, B. y G. Hernández. 2001. México solid wood products annual (Part 1, production and trade sections) 2001. USDA. Foreign Agricultural Service. $36 \mathrm{p}$.

Juárez, B. y G. Hernández. 2002. México solid wood products annual (Part 1, production and trade sections) 2002. USDA. Foreign Agricultural Service. $35 \mathrm{p}$.

Juárez, B. y G. Hernández. 2003. México solid wood products annual (Part 1) 2003. USDA. Foreign Agricultural Service. $33 p$.

Juárez, B. y M. Arceo. 2004. México solid wood products annual report (Part 1, production and trade sections) 2004. USDA. Foreign Agricultural Service. $36 \mathrm{p}$.

Quiñonez, E. G. 1998. Los productos forestales en los mercados de futuros. Tesis de Maestría en Ciencias. División de Ciencias Fores- 
tales. Universidad Autónoma Chapingo. México. 158 p.

Secretaría de Medio Ambiente, Recursos Naturales y Pesca (SEMARNAP). 1998. Anuario estadístico de la producción forestal 1995. Subsecretaría de Recursos Naturales; Dirección General Forestal. México. 126 p.

Secretaría de Medio Ambiente, Recursos Naturales y Pesca (SEMARNAP). 1998. Anuario estadístico de la producción forestal 1996. Subsecretaría de Recursos Naturales; Dirección General Forestal. México. 146 p.

Secretaría de Medio Ambiente, Recursos Naturales y Pesca (SEMARNAP). 1999. Anuario estadístico de la producción forestal 1997. Subsecretaría de Recursos Naturales; Dirección General Forestal. México. 144 p.

Secretaría de Medio Ambiente, Recursos Naturales y Pesca (SEMARNAP). 2000. Anuario estadístico de la producción forestal 1998. Subsecretaría de Recursos Naturales; Dirección General Forestal. México. 156 p.

Secretaría de Medio Ambiente y Recursos Naturales (SEMARNAT). 2001. Anuario estadístico de la producción forestal
1999. Subsecretaría de Recursos Naturales; Dirección General Forestal. México. 156 p.

Secretaría de Medio Ambiente y Recursos Naturales (SEMARNAT). 2001. Anuario estadístico de la producción forestal 2000. Subsecretaría de Recursos Naturales; Dirección General Forestal. México. 154 p.

Secretaría de Medio Ambiente y Recursos Naturales (SEMARNAT). 2003. Anuario estadístico de la producción forestal 2001. Subsecretaría de Recursos Naturales; Dirección General Forestal. México. 152 p.

Secretaría de Medio Ambiente y Recursos Naturales (SEMARNAT). 2004. Anuario estadístico de la producción forestal 2002. Subsecretaría de Recursos Naturales; Dirección General Forestal. México. 128 p.

Secretaría de Medio Ambiente y Recursos Naturales (SEMARNAT). 2005. Anuario estadístico de la producción forestal 2003. Subsecretaría de Recursos Naturales; Dirección General Forestal. México. 138 p. 
